International Journal of Current Advanced Research

ISSN: O: 2319-6475, ISSN: P: 2319-6505, Impact Factor: SJIF: 5.995

Available Online at www.journalijcar.org

Volume 6; Issue 12; December 2017; Page No. 8616-8621

DOI: http://dx.doi.org/10.24327/ijcar.2017.8621.1394

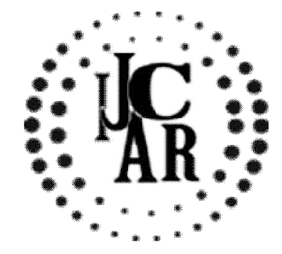

Research Article

\title{
A CLINICAL STUDY OF ACUTE INTESTINAL OBSTRUCTION IN ADULTS AT A TERTIARY CARE CENTRE IN NORTH INDIA
}

\author{
Junaid Alam., Aditya Varshney*., Mohhamad Aslam and Yusuf Afaque
}

Department of Surgery, Jawaharlal Nehru Medical College, Aligarh Muslim University, Aligarh, Uttar Pradesh, India, Pin Code- 202001

\section{A R T I C L E I N F O}

\section{Article History:}

Received $18^{\text {th }}$ September, 2017

Received in revised form $10^{\text {th }}$

October, 2017

Accepted $06^{\text {th }}$ November, 2017

Published online $28^{\text {th }}$ December, 2017

\section{Key words:}

Intestinal obstruction, abdominal pain, Ileocaecal tuberculosis, Resection and Ostomy, Outcome

\begin{abstract}
A B S T R A C T
Introduction- Intestinal obstruction occurs due to the failure of passage of contents through intestine. It can be because of a mechanical or functional pathology. Main causes of Intestinal obstruction may vary from country to country or among zones within a specific country. The aim of this study was to evaluate the etiology, presentation, management strategies, and outcomes of patients with acute mechanical Intestinal obstruction at a tertiary care hospital in Uttar Pradesh, North India.

Material and Methods- This prospective study was conducted in Department of Surgery, Jawaharlal Nehru Medical College Hospital, Aligarh Muslim University, Aligarh, India between October 2015 to September 2017. Total 263 patients were enrolled in our study who were diagnosed to have acute intestinal obstruction.

Observation and Results- Acute intestinal obstruction was diagnosed with males preponderance $(66.15 \%)$. The commonest age group affected was 41-50 years. Regarding clinical presentation of our patients, Abdominal pain was the most common presenting symptom and abdominal distension was the most common physical finding on clinical examination. The most common radiological finding was multiple air fluid levels seen on X-ray abdomen. In our patients, the main cause of obstruction was Ileocaecal tuberculosis followed by Adhesions and Bands. Small bowel obstruction was present in $81.36 \%$ cases and large bowel obstruction in $18.63 \%$ cases. The most common surgical procedure was segmental bowel resection with end to end anastomosis. Most of the cases recovered without any complications $(78.32 \%)$. Wound dehiscence, burst abdomen was the major cause of morbidity. 5.32\% mortality rate was reported in our study during post operative period and this was commonly seen in patients with Strangulated hernia and increased age.

Conclusion- Ileocaecal tuberculosis was the main causes of acute intestinal obstruction in our region. An algorithmic diagnostic approach based on different radio-logical imaging, blood investigations, biopsy and appropriate management with a rational combination of antitubercular therapy can reduce the morbidity of this easily curable yet potentially lethal disease.
\end{abstract}

Copyright $(2017$ Junaid Alam et al. This is an open access article distributed under the Creative Commons Attribution License, which permits unrestricted use, distribution, and reproduction in any medium, provided the original work is properly cited.

\section{INTRODUCTION}

Intestinal obstruction occurs due to the failure of passage of contents through intestine. It can be because of a mechanical or functional pathology. Now a days, acute mechanical intestinal obstruction is one of the main causes of surgical admissions in most emergency departments worldwide ${ }^{[1]}$. It is significant cause of morbidity and mortality, especially when findings are associated with bowel gangrene or perforation ${ }^{[2]}$. The etiology of intestinal obstruction may vary from country to country or among zones within a specific country ${ }^{[3]}$ therefore knowledge of the disease patterns and outcomes may raise the index of suspicion and reduces delays in diagnosis, operative intervention.

*Corresponding author: Aditya Varshney

Department of Surgery, Jawaharlal Nehru Medical College, Aligarh Muslim University, Aligarh, Uttar Pradesh, India, Pin Code- 202001
This is especially helpful in settings where diagnostic modalities are limited so making a definitive diagnosis may be challenging. The aim of this study was to evaluate the etiology, presentation, management strategies, and outcomes of patients with acute mechanical intestinal obstruction at a tertiary care hospital in western Uttar Pradesh, North India.

\section{Aims and Objectives}

- To study the incidence and different etiologies of intestinal obstruction.

- To study the different modes of presentation and its management.

- To study the role of imaging studies in determining the site of obstruction and its etiology.

- To study the morbidity and mortality rates in acute intestinal obstruction. 


\section{MATERIALS AND METHODS}

This prospective study was conducted in Department of Surgery, Jawaharlal Nehru Medical College Hospital, Aligarh Muslim University, Aligarh, India between October 2015 to September 2017. Total 263 patients were enrolled in our study who were diagnosed to have acute intestinal obstruction based on clinical, biochemical, radiological, pathological features. Final diagnosis was made at exploratory laparotomy. The cause of obstruction, site of obstruction and the performed operative procedure were recorded. A biopsy was taken where required for histopathological confirmation. Post operative complications, outcome and mortality were observed. All observations were discussed and compared with recent literature and derived final conclusions.

\section{Inclusion Criteria}

- $\quad$ Patients with age $\geq 15$ years.

- All patients presented to emergency department with features of intestinal obstruction and managed surgically.

\section{Exclusion Criteria}

- Patients who didn’t give consent for participation.

- Patients who were managed conservatively without surgical intervention.

\section{Observations and Results}

A total of 263 patients with diagnosis of acute intestinal obstruction were included in our study. Table 1 shows that out of the 263 patients, 61 were between 41 and 50 years $(23.19 \%)$ and it was most common age group diagnosed with acute intestinal obstruction. Table 2 shows that the incidence of intestinal obstruction was more in males $(66.15 \%)$ as compare to females $(33.84 \%)$. Table 3 shows that the most common clinical feature was abdominal pain followed by abdominal distension, obstipation, and vomiting. Table 4 shows that most common radiological feature was multiple air-fluid level followed by dilated bowel loops. Table 5 shows that out of the total 263 patients, 214 patients $(81.36 \%)$ had an obstruction in the small intestine and 49 patients $(18.63 \%)$ had an obstruction in the large intestine. Table 6 shows that in 51 patients $(19.39 \%)$ ileocecal tuberculosis was cause of obstruction and it was the most common cause followed by adhesions and bands (14.82\%), strictures $(12.16 \%)$, obstructed inguinal hernia $(11.03 \%)$, post operative adhesions (10.64\%), large bowel tumors $(8.74 \%)$, small bowel tumors $(7.22 \%)$, worm infestations $(3.81 \%)$, sigmoid volvulus $(3.42 \%)$, incisional hernia $(3.42 \%)$, femoral hernia (1.14\%), umbilical/ paraumbilical hernia $(0.76 \%)$, internal hernia $(0.76 \%)$, intussusceptions $(0.76 \%)$ and unknown etiology in $1.91 \%$ cases respectively. Table 7 shows that in 28 patients $(10.64 \%)$, obstruction was due to postoperative adhesions. Table 8 shows distribution of patients according to the surgical procedure performed. Segmental bowel resection and end to end anastomosis was done in 73 patients $(27.76 \%)$, Adhesiolysis in 59 patients $(22.43 \%)$, Resection and ostomy in 55 patients $(20.91 \%)$, Hernia repair in 34 patients $(12.93 \%)$, Strictureplasty in 22 patients $(8.36 \%)$, Detorsion and decompression in 10 patients $(3.80 \%)$, Enterotomy in 6 patients $(2.28 \%)$ and Massaging of worms into the colon in 4 patients $(1.52 \%)$ respectively. Table 9 shows that incidence of bowel ischemia, necrosis, and perforation was more in large bowel obstruction group as compare to small bowel obstruction group. Table 10 shows that post operative stage was uneventful in most of patients (78.32\%). Morbidity occurred in 43 patients $(16.34 \%)$ includes wound dehiscence in 24 patients $(9.12 \%)$, basal atelectasis in 14 patients $(5.32 \%)$, enterocutaneous fistula in 6 patients $(2.28 \%)$, prolonged ileus in 6 patients $(2.28 \%)$ and burst abdomen in 7 patients $(2.66 \%)$. Mortality was reported in 14 patients $(5.32 \%)$ during post operative period.

Table 1 Age wise distribution

\begin{tabular}{cc}
\hline Age (Years) & $\begin{array}{c}\text { No. of } \\
\text { patients } \\
\mathbf{n = 2 6 3}(\mathbf{2})\end{array}$ \\
\hline $15-20$ & $18(6.84 \%)$ \\
$21-30$ & $29(11.03 \%)$ \\
$31-40$ & $37(14.07 \%)$ \\
$41-50$ & $61(23.19 \%)$ \\
$51-60$ & $53(20.15 \%)$ \\
$61-70$ & $39(14.82 \%)$ \\
$\geq 71$ & $26(9.88 \%)$ \\
\hline
\end{tabular}

Table 2 Sex distribution

\begin{tabular}{cc}
\hline Sex & $\begin{array}{c}\text { No. of } \\
\text { patients } \\
\mathbf{n = 2 6 3 ( \% )}\end{array}$ \\
\hline Male & $174(66.15 \%)$ \\
Female & $89(33.84 \%)$ \\
\hline
\end{tabular}

Table 3 Clinical features

\begin{tabular}{cc}
\hline Clinical features & $\begin{array}{c}\text { No. of patients } \\
\text { n=263(\%) }\end{array}$ \\
\hline Abdominal pain & $242(92.01 \%)$ \\
Abdominal distension & $229(87.07 \%)$ \\
Obstipation & $221(84.03 \%)$ \\
Vomiting & $192(73 \%)$ \\
Increased bowel sound & $176(66.92 \%)$ \\
Absent bowel sound & $54(20.53 \%)$ \\
Tenderness & $207(78.07 \%)$ \\
Groin swelling & $32(12.16 \%)$ \\
Visible peristalsis & $49(18.63 \%)$ \\
Guarding & $138(52.47 \%)$ \\
Rigidity & $37(14.07 \%)$ \\
Palpable mass & $09(3.42 \%)$ \\
\hline
\end{tabular}

Table 4 Radiological features

\begin{tabular}{cc}
\hline $\begin{array}{c}\text { Radiological } \\
\text { features }\end{array}$ & $\begin{array}{c}\text { No. of patients } \\
\mathbf{n}=\mathbf{2 6 3}(\%)\end{array}$ \\
\hline Multiple air fluid & $223(84.79 \%)$ \\
levels & $199(75.66 \%)$ \\
Dilated bowel loops & $9(3.42 \%)$ \\
Coffee-bean sign & 9 \\
\hline
\end{tabular}

Table 5 Site of Intestinal obstruction

\begin{tabular}{cc}
\hline $\begin{array}{c}\text { Site of Intestinal } \\
\text { obstruction }\end{array}$ & $\begin{array}{c}\text { No. of patients } \\
\text { n=263(\%) }\end{array}$ \\
\hline Small intestine & $214(81.36 \%)$ \\
Large intestine & $49(18.63 \%)$ \\
\hline
\end{tabular}

Table 6 Etiology of Intestinal obstruction

\begin{tabular}{cc}
\hline Etiology & $\begin{array}{c}\text { No. of patients } \\
\text { n=263(\%) }\end{array}$ \\
\hline Ileocecal tuberculosis & $51(19.39 \%)$ \\
Primary Adhesions and Bands & $39(14.82 \%)$ \\
Strictures & $32(12.16 \%)$ \\
Obstructed inguinal hernia & $29(11.03 \%)$ \\
Post operative Adhesions & $28(10.64 \%)$ \\
Large bowel tumors & $23(8.74 \%)$ \\
Small bowel tumors & $19(7.22 \%)$ \\
Worm infestation & $10(3.81 \%)$ \\
Sigmoid Volvulus & $09(3.42 \%)$ \\
Incisional hernia & $09(3.42 \%)$ \\
Femoral hernia & $03(1.14 \%)$ \\
Umbilical/ Paraumbilical hernia & $02(0.76 \%)$ \\
Internal hernia & $02(0.76 \%)$ \\
Intussusception & $02(0.76 \%)$ \\
Unknown & $05(1.91 \%)$ \\
\hline
\end{tabular}




\section{A Clinical Study of Acute Intestinal Obstruction in Adults at A Tertiary Care Centre in North India}

Table 7 Previous operations in 28 cases of post-operative adhesive obstruction

\begin{tabular}{cc}
\hline Previous operations & $\begin{array}{c}\text { No. of } \\
\text { patients } \\
(\mathbf{n = 2 8 )}\end{array}$ \\
\hline Closure of ileal perforation & 7 \\
Appendectomy & 6 \\
Closure of Gastro-duodenal & 5 \\
perforation & 5 \\
Caesarean section & 2 \\
Salpingectomy & 3 \\
Not known &
\end{tabular}

Table 8 Types of operative procedure performed

\begin{tabular}{cc}
\hline Procedures & Cases n=263(\%) \\
\hline Segmental bowel resection with & $73(27.76 \%)$ \\
end to end anastomosis & $57(21.67 \%)$ \\
Adhesionlysis & $55(20.91 \%)$ \\
Resection and ostomy & $34(12.93 \%)$ \\
Hernia repair & $17(6.46 \%)$ \\
Strictrueplasty & $10(3.80 \%)$ \\
Detorsion and decompression & $07(2.66 \%)$ \\
Band release & $06(2.28 \%)$ \\
Enterotomy & $04(1.52 \%)$ \\
Massaging of worms into the & colon
\end{tabular}

Table 9 Incidence of Bowel ischemia, necrosis, and Perforation

\begin{tabular}{cccc}
\hline Value & $\begin{array}{c}\text { Small bowel } \\
\text { obstruction } \\
\text { group(n=214) }\end{array}$ & $\begin{array}{c}\text { Large bowel } \\
\text { obstruction } \\
\text { group(n=49) }\end{array}$ & $\begin{array}{c}\text { Total study } \\
\text { group(n=263) }\end{array}$ \\
\hline Ischemia & $27(12.61 \%)$ & $7(14.28 \%)$ & $34(12.92 \%)$ \\
Necrosis & $14(6.54 \%)$ & $6(12.24 \%)$ & $20(7.60 \%)$ \\
Perforation & $7(3.27 \%)$ & $4(8.16 \%)$ & $11(4.18 \%)$ \\
\hline
\end{tabular}

Table 10 Outcomes

\begin{tabular}{cc}
\hline Outcomes & $\begin{array}{c}\text { No. of patients } \\
\text { n=263(\%) }\end{array}$ \\
\hline Uneventful recovery & $206(78.32 \%)$ \\
Morbidity & $43(16.35 \%)$ \\
Mortality & $14(5.32 \%)$ \\
\hline
\end{tabular}

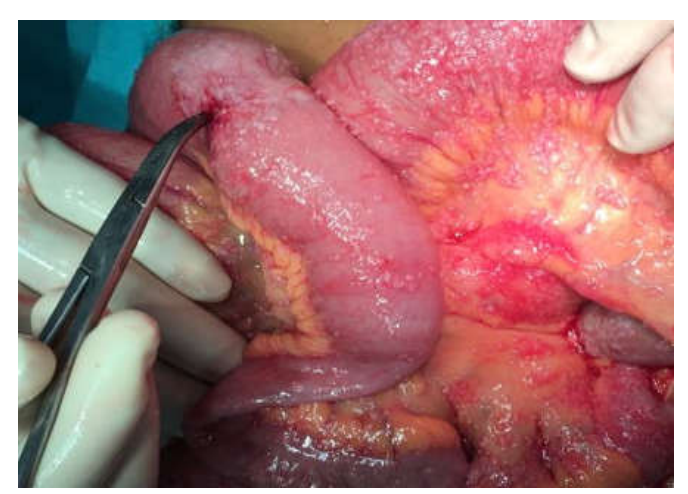

Fig 1 Ileocaecal tuberculosis with stricture

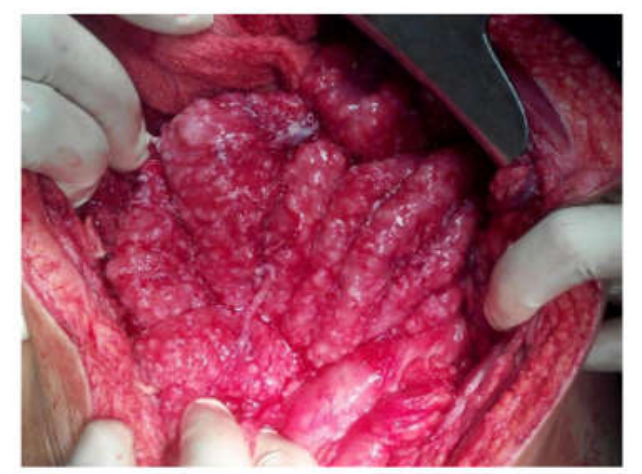

Fig 2 Ileocaecal and mesenteric tuberculosis with adhesions

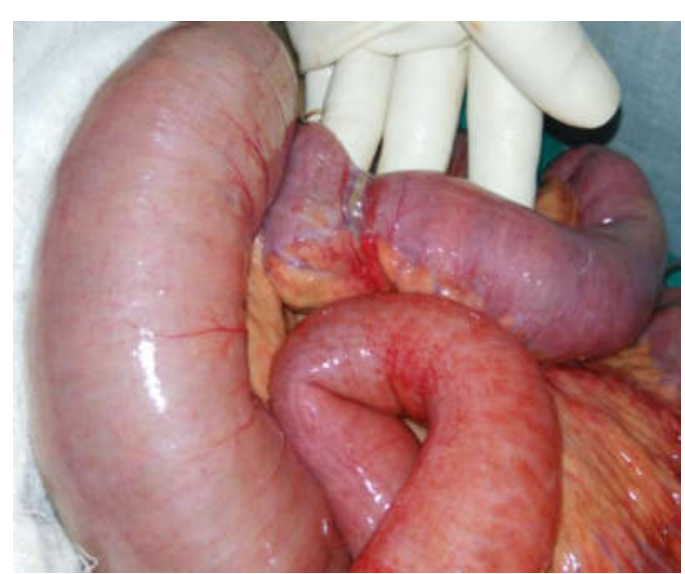

Fig 3 Band causing intestinal obstruction

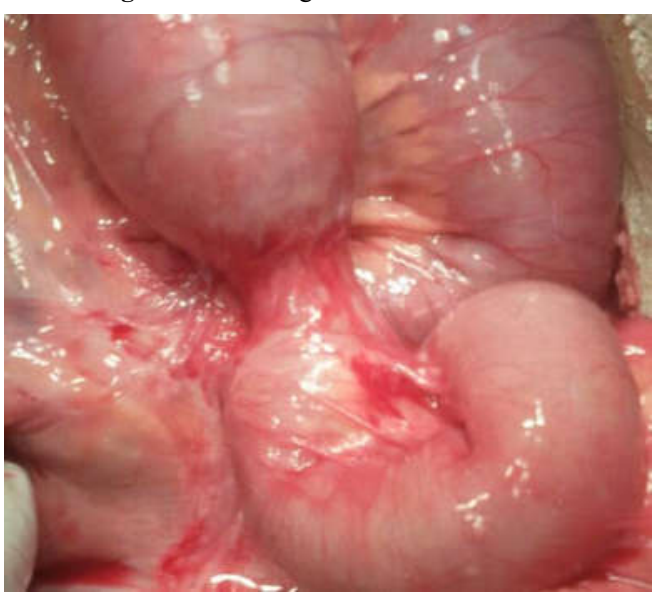

Fig 4 Stricture causing intestinal obstruction

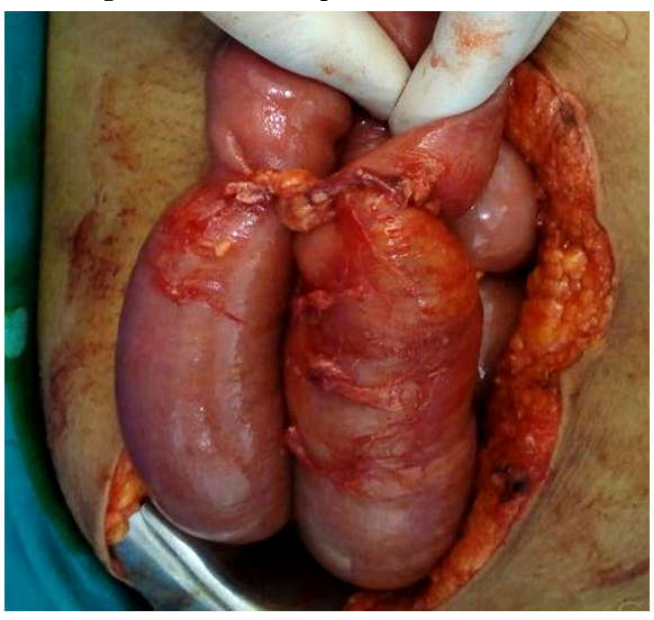

Fig 5 Adhesions causing intestinal obstruction

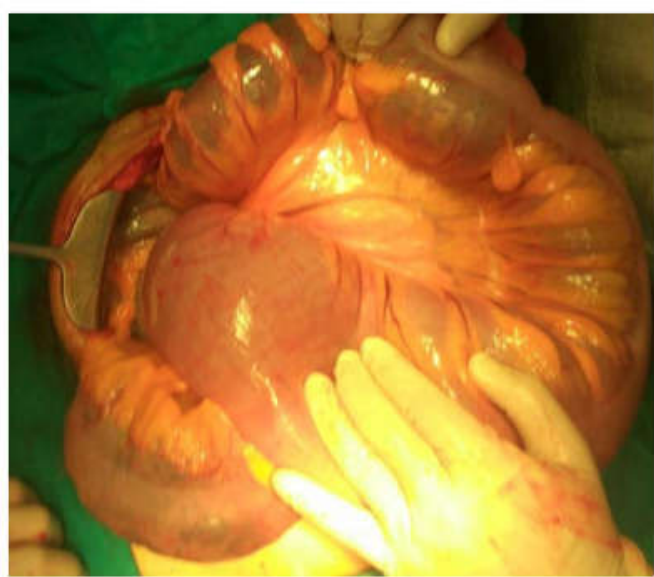

Fig 6 Sigmoid volvulus causing intestinal obstruction 


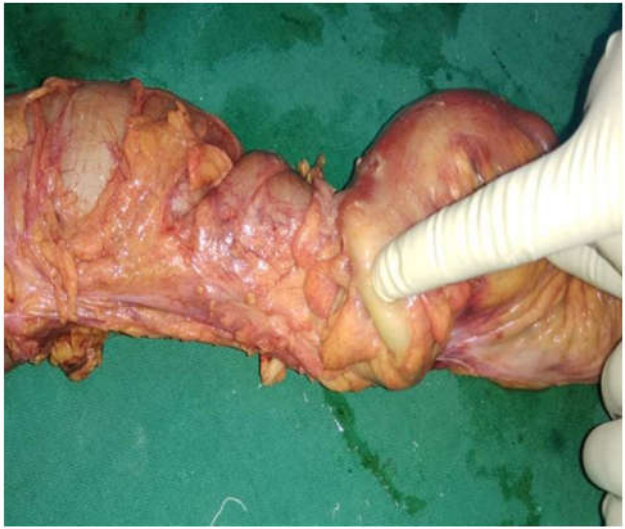

Fig 7 The surgical specimen after the en bloc resection of the ileum with intussusception

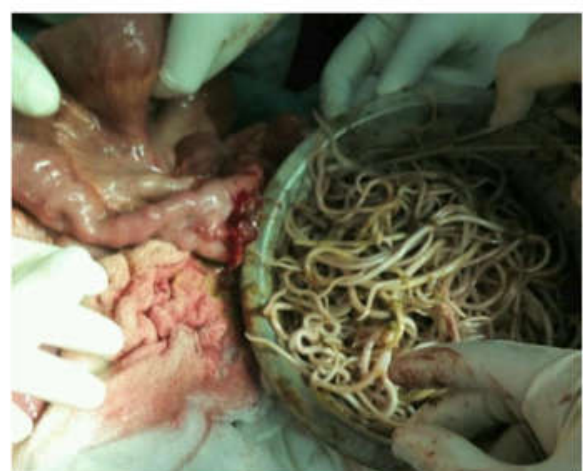

Fig 8 Worm infestation in a patient of intestinal obstruction

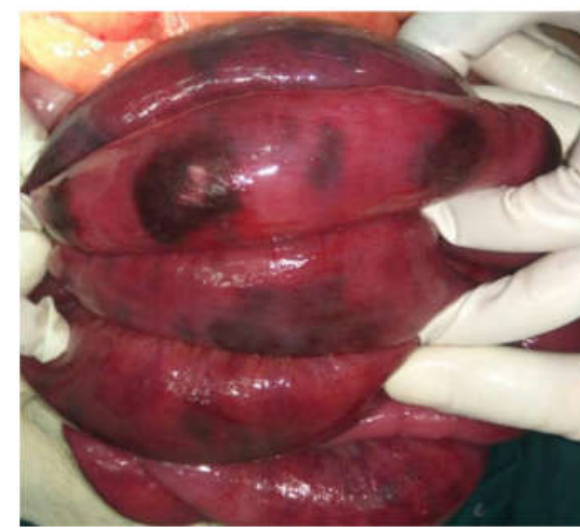

Fig 9 Dialated bowel loops with ischemia in intestinal obstruction

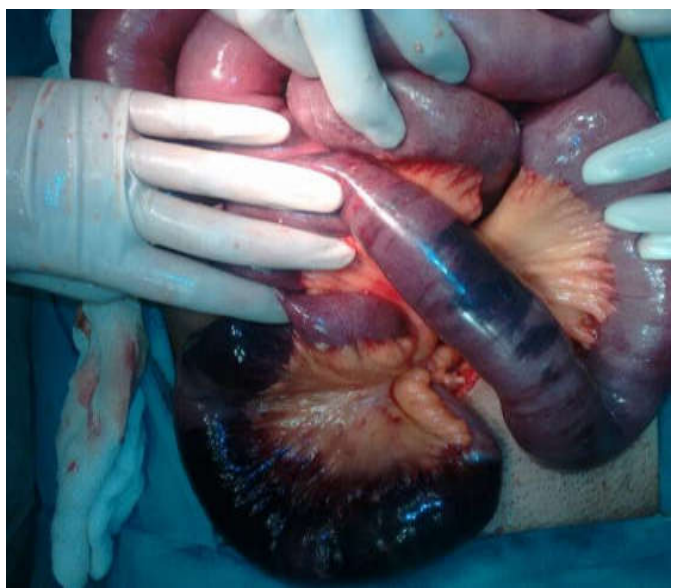

Fig10 Dialated bowel loops with necrosis in intestinal obstruction

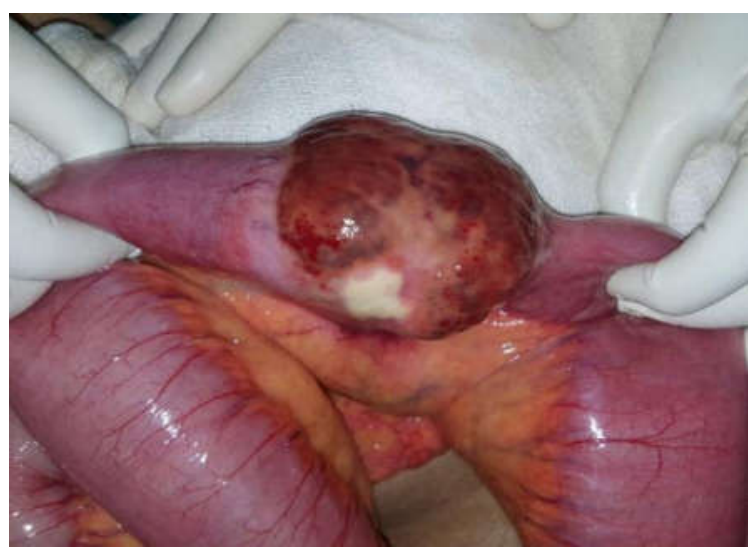

Fig 11 Primary lymphoma of the small bowel causing obstruction

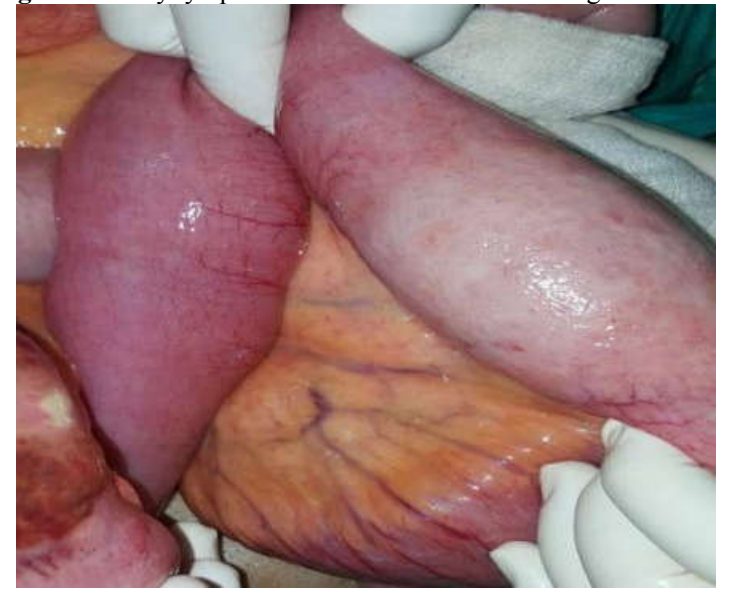

Fig 12 Intraluminal growth causing bowel obstruction

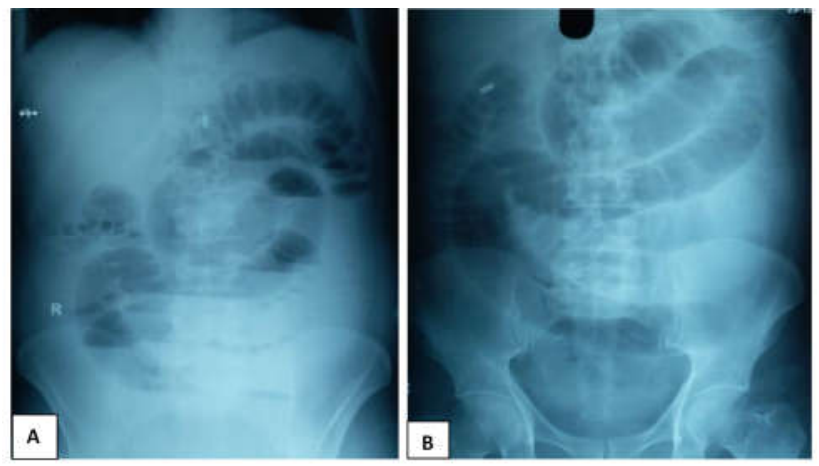

Fig 13 Plain Abdominal radiographs of a patient with complete small bowel obstruction. A, erect film shows multiple air fluid levels in a stepwise pattern. B, supine film shows centrally located dilated bowel loops with valvulae conniventes

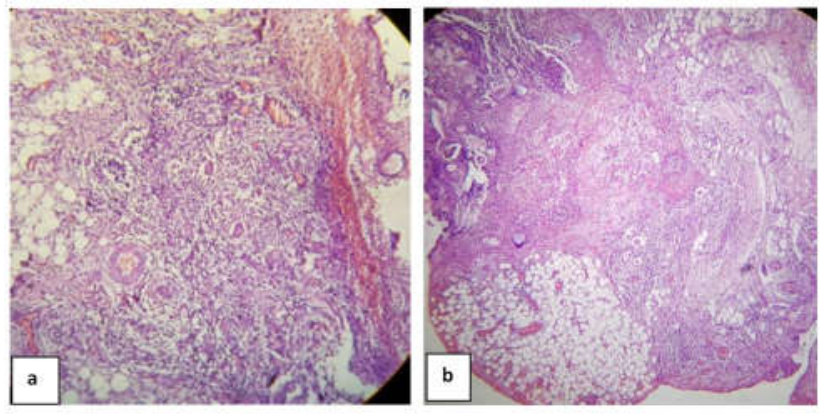

Fig 14 Photomicrographs of sections from mesenteric lymphnode showing (a-b) multiple caseating epitheloid cell granulomas with langhans giant cells.Histomorphological features consistent with intestinal tuberculosis. $[\mathrm{H} \& \mathrm{E}$ stain, a) $\times 40$, b) $\times 40]$ 


\section{DISCUSSION}

The present study was carried out with an aim to study the age and sex distributions, various etiologies, clinical presentations, treatments given and outcomes of acute intestinal obstruction.

Intestinal obstruction remains one of the most common surgical diagnosis made in emergency departments worldwide $^{[1]}$, management of which requires quick, appropriate diagnosis, rational and effective therapy ${ }^{[4]}$.

In our study most common age group was between 41 and 50 years followed by 51-60 years with male predominance $(66.15 \%)$. It is consistent with the study conducted by Souvik et $a l^{[3]}$ and Deshmukh et $a l^{[5]}$. Regarding clinical presentation of our patients, abdominal pain was the most common presenting symptom and abdominal distension was the most common physical finding on clinical examination. Additionally absence of passage of flatus and/or stool, vomiting, nausea were frequent symptoms on arrival. Our results are comparable to study conducted by Souvik et $a l^{[3]}$ and Khan at $\mathrm{el}^{[6]}$.

The most common radiological finding was multiple air fluid levels followed by dilated bowel loops. The observations are comparable to a study conducted by Malik et al. ${ }^{[1]}$ Small bowel obstruction was present in $81.36 \%$ patients and large bowel obstruction in $18.63 \%$ patients in our study. A study conducted by Markogiannakis et al. ${ }^{[7]} 71.1 \%$ of the obstruction was located on the small bowel. The most common underlying cause of obstruction in our study was found to be ileocecal tuberculosis. This is contrary to the results of other study, where obstructed inguinal hernia was the commonest cause of acute intestinal obstruction ${ }^{[5,8]}$ followed by Adhesions and Bands ${ }^{[1,7]}$. Intestinal obstruction resulting from tuberculosis has been reported to be more prevalent in patients with low socioeconomic status ${ }^{[9]}$. This observation is consistent with our study where most of patients had either primary or no formal education and more than seventy five percent of them were unemployed. The majority of patients in the present study came from the rural areas located a considerable distance from the study area. Similar observations were reported by other studies also ${ }^{[9-11]}$. This observation has an implication on accessibility to health care facilities and awareness of the disease as delayed presentation increases morbidity and mortality many folds.

The most common surgical procedure was segmental bowel resection with end to end anastomosis. Next common procedure was adhesiolysis, resection and ostomy respectively. Most of the cases recovered without any complications $(78.32 \%)$. Infection propagating to wound dehiscence, burst abdomen was the major cause of morbidity and was seen in $11.78 \%$ cases. $5.32 \%$ mortality rate was reported in our study during post operative period and commonly seen in patients with strangulated hernia and increased age. In $2.28 \%$ cases death occurred due to acute respiratory distress syndrome. This observation is comparable to a similar study conducted by Adhikari et $a l^{[3]}$, Ohene et $a l^{[12]}$.

\section{SUMMARY AND CONCLUSIONS}

As a summary, in our scenario, Ileocecal tuberculosis remains to be the most common cause followed by adhesions and bands. Patients can be diagnosed on time based on a high index of suspicion in areas where tuberculosis is common. An algorithmic diagnostic approach based on different radiological imaging, blood investigations, endoscopy, biopsy and treatment with a rational combination of anti-tubercular therapy can reduce the morbidity of this easily curable yet potentially lethal disease. Old age, delayed presentation to hospital, associated comorbid conditions increases the morbidity and mortality. Poverty and illiteracy among the people are the additional factors to this problem. Early diagnosis and timely intervention may decrease morbidity and mortality of these patients. Malignancies were common in large bowel obstruction patients as compare to small bowel obstruction patients.

To conclude, acute intestinal obstruction remains an important surgical emergency with significant morbidity as well as mortality. Great caution should be taken while treating patients with acute mechanical bowel obstruction since the incidence of bowel ischemia, necrosis and perforation is significantly high. Clinical findings combined with radiological findings can diagnose intestinal obstruction substantially. Though a proportion of these patients can be managed conservatively, immediate operative intervention was required in substantial proportion. Success in the management of acute intestinal obstruction depends mainly upon prompt diagnosis, adequate resuscitation and skilful management.

\section{References}

1. Malik AM, Shah M, Pathan R, Sufi K. Pattern of acute intestinal obstruction: is there a change in the underlying etiology? Saudi J Gastroenterol. 2010;(4):272-4.

2. Ellis H. The clinical significance of adhesions: focus on intestinal obstruction. Eur J Surg Suppl Acta Chir Suppl. 1997;(577):5-9.

3. Souvik A, Zahid Hossein M, Amitabha D, Nilanjan M, Udipta R. Etiology and Outcome of Acute Intestinal Obstruction: A Review of 367 Patients in Eastern India. Saudi J Gastroenterol Off J Saudi Gastroenterol Assoc. 2010 Oct;16(4):285-7.

4. Ntakiyiruta G, Mukarugwiro B. The pattern of intestinal obstruction at Kibogola Hospital, a rural hospital in Rwanda. East Cent Afr J Surg. 2009 Jan 1;14(2):103-8.

5. Deshmukh SN, Maske AN. Pattern of dynamic intestinal obstruction in adults at tertiary care centre. Int Surg J. 2016 Dec 8;3(2):492-6.

6. Khan JS, Alam J, Hassan H, Iqbal M. Pattern of intestinal obstruction a hospital based study. Pak Armed Forces Med J. 2007 Dec;57(4):295-9.

7. Markogiannakis H, Messaris E, Dardamanis D, Pararas N, Tzertzemelis D, Giannopoulos $\mathrm{P}$, et al. Acute mechanical bowel obstruction: Clinical presentation, etiology, management and outcome. World J Gastroenterol WJG. 2007 Jan 21;13(3):4327.

8. Priscilla SB, Edwin IA, Kumar K, Gobinath M, Arvindraj VM, Anandan H. A Clinical Study on Acute Intestinal Obstruction. Int J Sci Study. 2017 May;1(5):107-10.

9. Debi U, Ravisankar V, Prasad KK, Sinha SK, Sharma AK. Abdominal tuberculosis of the gastrointestinal tract: Revisited. World J Gastroenterol WJG. 2014 Oct 28;20(40):14831-40. 
10. Barman B, Nongpiur A, Bora K, Synrem E, Phukan P, Sarma K. Clinical and laboratory presentation of abdominal tuberculosis in Shillong, Meghalaya: Experience from Northeast India. Indian J Med Spec. 2017 Jul 1;8(3):134-8.

11. Hatwal D, Kumar A, Batra N. Abdominal Tuberculosis in Uttarakhand: A diagnostic Dilemma. Indian J Pathol Oncol. 2017 Apr;4(2):188-92.
12. Ohene-Yeboah M, Adippah E, Gyasi-Sarpong K. Acute intestinal obstruction in adults in kumasi, ghana. Ghana Med J. 2006 Jun;40(2):50-4.

\section{How to cite this article:}

Junaid Alam et al (2017) 'A Clinical Study of Acute Intestinal Obstruction in Adults at A Tertiary Care Centre in North India', International Journal of Current Advanced Research, 06(12), pp. 8616-8621.

DOI: http://dx.doi.org/10.24327/ijcar.2017.8621.1394 